\title{
Acute liver failure caused by mushroom poisoning: a case report and review of the literature
}

\author{
This article was published in the following Dove Press journal: \\ International Medical Case Reports Journal \\ 21 November 2013 \\ Number of times this article has been viewed
}

\author{
Abdulsamet Erden' \\ Kübra Esmeray' \\ Hatice Karagöz' \\ Samet Karahan' \\ Hasan Hüseyin Gümüșçü' \\ Mustafa Bașak' \\ Ali Çetinkaya' \\ Deniz Avcı' \\ Orhan Kürșat Poyrazoğlu² \\ 'Internal Medicine Department, \\ ${ }^{2}$ Gastroenterology Department, \\ Kayseri Training and Research \\ Hospital, Kayseri, Turkey
}

\begin{abstract}
It is estimated that there are over 5,000 species of mushrooms worldwide. Some of them are edible and some are poisonous due to containing significant toxins. In more than $95 \%$ of mushroom toxicity cases, poisoning occurs as a result of misidentification of the mushroom by an amateur mushroom hunter. The severity of mushroom poisoning may vary, depending on the geographic location where the mushroom is grown, growth conditions, the amount of toxin delivered, and the genetic characteristics of the mushroom. Amanita phalloides is the most common and fatal cause of mushroom poisoning. This mushroom contains amanitins, which are powerful hepatotoxins that inhibit RNA polymerase II in liver. Mushroom poisoning is a relatively rare cause of acute liver failure. A 63-year-old male patient was admitted to the emergency room with weakness, nausea, vomiting, and diarrhea. He reported ingesting several wild mushrooms about 36 hours earlier. In this article we report a case of lethal Amanita phalloides intoxication from stored mushrooms.
\end{abstract}

Keywords: acute liver failure, Amanita phalloides, mushroom, poisoning

\section{Introduction}

Mushroom poisoning is a major health risk in rural areas, and it is presumed that over 5,000 species of mushrooms are present worldwide. ${ }^{1}$ In more than $90 \%$ of cases of ingestion, the type of mushroom is unknown because of difficulties in the exact identification of mushroom species. ${ }^{2}$ Most of the ingested mushrooms are either nontoxic or only gastrointestinal irritants, resulting in mild to moderate toxic effects. ${ }^{3}$ Cyclopeptide toxins are responsible for the pathogenicity of mushrooms. Among these toxins, amatoxins have their most serious effect on the liver and account for $90 \%$ of fatal mushroom poisonings. ${ }^{4}$ This process is characterized by an asymptomatic incubation period followed by the gastrointestinal and hepatotoxic phases which progress to multiorgan failure and death. We report a case of lethal Amanita phalloides intoxication from stored mushrooms.

\section{Case}

A 63-year-old male patient was admitted to the emergency room with weakness, nausea, vomiting, and diarrhea. After specific query, he reported ingesting several wild mushrooms about 36 hours earlier. Severe nausea, vomiting, and diarrhea had set in 7-8 hours after ingestion. He had a medical history of hypertension and colon carcinoma. He had undergone surgery and had received chemotherapy two months earlier. Also, he had no metastasis in the liver, he did not consume alcohol, and he did not use any medication.
Correspondence: Samet Karahan Internal Medicine Department, Kayseri Training and Research Hospital, Kayseri Eğitim Araștırma Hastanesi, iç Hastalıkları Kliniği, 9 Blok 3, Kat Kocasinan, Kayseri 38010, Turkey Tel +905063020036

Email doktorsamet@yahoo.com 
On admission, he was awake and fully oriented, and all vital signs were normal. His physical examination was unremarkable except for dehydration. Arterial blood gas analysis was normal. Hepatitis B surface antigen, hepatitis B core antibody, immunoglobulin $\mathrm{M}$, and antihepatitis $\mathrm{C}$ antibody were found to be nonreactive. A hepatitis B virus DNA analysis was performed using the polymerase chain reaction and was determined to be negative. The patient was then admitted to the internal medicine intensive care unit. After performing a gastric lavage via a nasogastric tube, activated charcoal was initiated and continued at a dose of 50 grams every 6 hours. The patient was rehydrated via intravenous (iv) administration with $0.9 \%$ sodium chloride and $5 \%$ dextrose to guard against the risk of hypoglycemia. Simultaneously, silibinin, at a bolus dose of $5 \mathrm{mg} / \mathrm{kg}$ iv, was initiated and followed by a continuous iv infusion of $20 \mathrm{mg} / \mathrm{kg} /$ day. Acetylcysteine was given by continuous iv infusion for 21 hours, with a total dose of $300 \mathrm{mg} / \mathrm{kg}$ (150 mg/kg over 1 hour, followed by $50 \mathrm{mg} / \mathrm{kg}$ over 4 hours, followed by $150 \mathrm{mg} / \mathrm{kg}$ over 16 hours). Infusion of penicillin $\mathrm{G}$ in doses of 1,000,000 U/kg/day, multivitamin, and alpha lipoic acid were started. Treatments are summarized in Table 1. Complete blood count, biochemistry measurements, and blood gas monitoring were performed every 6 hours (Tables 2 and 3 ).

At 6 hours after his admission, aspartate aminotransferase (AST) was $880 \mathrm{U} / \mathrm{L}$; alanine aminotransferase (ALT) $665 \mathrm{U} / \mathrm{L}$; lactate dehydrogenase (LDH) 1,028 U/L; total bilirubin $4.9 \mathrm{mg} / \mathrm{dL}$; direct bilirubin $1.9 \mathrm{mg} / \mathrm{dL}$; prothrombine time (PT) 36.5 seconds; and international normalized ratio (INR) 3.11. His lactate level was normal. Vitamin K (menadion $20 \mathrm{mg} /$ day, iv) and metilprednisolone in doses of $1 \mathrm{mg} / \mathrm{kg} /$ day were started.

\section{Table I Treatments}

Gastric lavage
Activated charcoal ( 50 grams every 4 hours)
Rehydration with iv fluid $(0.9 \% \mathrm{NaCl}$ and $5 \%$ dextrose)
Silibinin (bolus dose of $5 \mathrm{mg} / \mathrm{kg}$ and continuous infusion of $20 \mathrm{mg} / \mathrm{kg} /$ day,
four equal doses)
Acetylcysteine (I50 mg/kg over I hour, followed by $50 \mathrm{mg} / \mathrm{kg}$ over
4 hours, followed by I50 mg/kg over 16 hours)
Penicillin G (I,000,000 U/kg/day, six equal doses)
Multivitamin complex containing vitamin A, D, E, C, BI, B2, B6, BI2, folic
acid, pantothenic acid, D-biotin, and nicotinamide; twice a day
Alpha lipoic acid; twice a day
Vitamin K iv; once a day
Fresh frozen plasma (I5 mL/kg)
Hemodialysis

Abbreviations: iv, intravenous; $\mathrm{NaCl}$, sodium chloride.
At 12 hours from admission, AST was 1,836 U/L; ALT 1,232 U/L; LDH 1,471 U/L; total bilirubin $7.2 \mathrm{mg} / \mathrm{dL}$; direct bilirubin $3.1 \mathrm{mg} / \mathrm{dL}$; PT 73.1 seconds; and INR 6.86. Upon arterial blood gas analysis, the patient had metabolic acidosis with a normal anion gap (AG) and respiratory alkalosis $(\mathrm{pH} 7.38$; partial pressure of carbon dioxide $\left[\mathrm{pCO}_{2}\right] 26.5 \mathrm{mmHg}$; partial pressure of oxygen $\left[\mathrm{pO}_{2}\right]$ $49.5 \mathrm{mmHg}$; bicarbonate $\left[\mathrm{HCO}_{3}\right] 17.8 \mathrm{mmol} / \mathrm{L}$; base excess $[\mathrm{BE}]-8.8 \mathrm{mmol} / \mathrm{L})$. Fresh frozen plasma were administrated at a dose of $15 \mathrm{~mL} / \mathrm{kg}$, and hemodialysis was performed for 3 hours.

At 30 hours the patient's general condition began to worsen. He was somnolent and mildly tachypneic. His AST level was 1,900 U/L; ALT 1,473 U/L; LDH 2,582 U/L; PT 76.5 seconds; INR 7.22; hemoglobin (Hb) $12.5 \mathrm{~g} / \mathrm{dL}$; and platelets (PLTs) $123,000 / \mathrm{mm}^{3}$. We consulted the committee for liver transplantation, but because of the patient's colon carcinoma, our application was not accepted. Current therapies were continued. Hemodialysis was performed again for 4 hours, and fresh frozen plasma was given again. After dialysis and fresh frozen plasma replacement, AST was 1,843 U/L; ALT 984 U/L; LDH 3,826 U/L; PT 42.6 seconds; and INR 3.71.

At 48 hours from the time of admission, AST was 1,207 U/L; ALT 1,797 U/L; LDH 4,318 U/L; total bilirubin $9.8 \mathrm{mg} / \mathrm{dL}$; direct bilirubin $3.3 \mathrm{mg} / \mathrm{dL}$; PT 47.7 seconds; INR 4.21; Hb $11.8 \mathrm{~g} / \mathrm{dL}$; and PLTs 33,000/. $\mathrm{mm}^{3}$. Arterial blood gas analysis revealed high AG metabolic acidosis with respiratory alkalosis $\left(\mathrm{pH} 7.36\right.$; $\mathrm{pCO}_{2} 20.3 \mathrm{mmHg}$; $\mathrm{pO}_{2}$ $52.3 \mathrm{mmHg} ; \mathrm{HCO}_{3} 14.7 \mathrm{mmol} / \mathrm{L}$; BE -13 mmol/L; and AG $25.3 \mathrm{mmol} / \mathrm{L}$ ). His fibrinogen level was in the normal range (200-400 mg/dL) and D-dimer concentration was elevated $(>2000 \mu \mathrm{g} / \mathrm{L})$. No schistocytes were apparent in a peripheral blood smear.

The patient had developed a flapping tremor. His blood ammonia level was $281 \mu \mathrm{g} / \mathrm{dL}$. Hepatic encephalopathy treatment, including $500 \mathrm{~mL}$ of branched chain amino acid solution (HepatAmine ${ }^{\circledR}$; B. Braun Medical Inc, Irvine, CA, USA) over a 12-hour period and infusion of ornithineaspartate at a dose of $20 \mathrm{~g} /$ day and lactulose at a dose of $45 \mathrm{~g} /$ day, was started.

At 54 hours AST was 3,570 U/L; ALT 3,282 U/L; LDH 4,379 U/L; total bilirubin $12.4 \mathrm{mg} / \mathrm{dL}$; PT 111 seconds; INR 11.05; and PLTs 29,000/ $\mathrm{mm}^{3}$. Hemodialysis was performed for 4 hours and fresh frozen plasma was given again. At 60 hours, PT was 34.6 seconds; INR 2.92; Hb 8.6 g/dL; and PLTs $12,000 / \mathrm{mm}^{3}$. One unit of erythrocyte suspension was given. 
Table 2 Complete blood count and biochemistry measurements

\begin{tabular}{|c|c|c|c|c|c|c|c|c|c|}
\hline & $\begin{array}{l}\text { PT } \\
\text { (seconds) }\end{array}$ & INR & $\begin{array}{l}\text { AST } \\
\text { (U/L) }\end{array}$ & $\begin{array}{l}\text { ALT } \\
\text { (U/L) }\end{array}$ & $\begin{array}{l}\text { LDH } \\
\text { (U/L) }\end{array}$ & $\begin{array}{l}\text { TB } \\
\text { (mg/dL) }\end{array}$ & $\begin{array}{l}\text { DB } \\
(\mathrm{mg} / \mathrm{dL})\end{array}$ & $\begin{array}{l}\text { PLTs } \\
\left(/ \mathrm{mm}^{3}\right)\end{array}$ & $\begin{array}{l}\mathrm{Hb} \\
(\mathrm{g} / \mathrm{dL})\end{array}$ \\
\hline On admission & 20.4 & 1.6 & 701 & 400 & 967 & 2.5 & 0.6 & 384,000 & 17 \\
\hline 6 hours & 36.5 & 3.11 & 880 & 665 & $\mathrm{I}, 028$ & 4.9 & 1.9 & & \\
\hline 12 hours & 73.1 & 6.86 & I,836 & 1,232 & $|, 47|$ & 7.2 & 3.1 & 312,000 & 16.7 \\
\hline 18 hours & 32.4 & 2.71 & 907 & 963 & $\mathrm{I}, 694$ & 8.3 & 3.3 & 165,000 & 13.6 \\
\hline 24 hours & 56.1 & 5.08 & $\mathrm{I}, 375$ & 1,220 & 2,024 & 8.9 & 3.6 & 162,000 & 13 \\
\hline 30 hours & 76.5 & 7.22 & 1,900 & $\mathrm{I}, 473$ & 2,582 & 9.4 & 4.4 & 123,000 & 12.5 \\
\hline 36 hours & 42.6 & 3.71 & $\mathrm{I}, 843$ & 984 & 3,826 & 8.2 & 3.7 & & \\
\hline 42 hours & 77.1 & 7.29 & $\mathrm{I}, 753$ & 454 & 4,220 & 8.6 & 3.1 & 58,000 & 11.6 \\
\hline 48 hours & 47.7 & 4.21 & $\mathrm{I}, 207$ & $\mathrm{I}, 797$ & 4,318 & 9.8 & 3.3 & 33,000 & 11.8 \\
\hline 54 hours & $\mathrm{III}$ & 11.05 & 3,570 & 3,282 & 4,379 & 12.4 & 3.5 & 29,000 & 12.1 \\
\hline 60 hours & 34.6 & 2.92 & 2,218 & 2,303 & 2,876 & 10.1 & 2.7 & 12,000 & 8.6 \\
\hline 66 hours & 62.7 & 5.76 & 1,676 & 2,053 & 2,502 & 9.9 & 2.5 & 11,000 & 10.5 \\
\hline 72 hours & 59.2 & 5.39 & 1,116 & 1,825 & & & & 10,000 & 11.7 \\
\hline 78 hours & 100.6 & 9.87 & 1,096 & 2,004 & 1,615 & 11.5 & 2.4 & 7,000 & 11 \\
\hline 84 hours & 50.5 & 4.5 & 432 & 893 & & 13.4 & 2.6 & 40,000 & 9.7 \\
\hline 90 hours & 50.3 & 4.48 & 354 & 863 & & 10.7 & 2.6 & 36,000 & 9.4 \\
\hline 96 hours & 77.3 & 7.31 & 329 & 855 & & & & 13,000 & 8.3 \\
\hline
\end{tabular}

Abbreviations: ALT, alanine aminotransferase; AST, aspartate aminotransferase; DB, direct bilirubin; Hb, hemoglobin; INR, international normalized ratio; LDH, lactate dehydrogenase; PLTs, platelets; PT, prothrombine time; TB, total bilirubin.

At 72 hours after admission, the patient lost consciousness. His body temperature was $38.2^{\circ} \mathrm{C}$, pulse rate 112 beats per minute, respiratory rate 32 breaths per minute, and blood pressure $89 / 57 \mathrm{mmHg}$. Meropenem was started at a dose of $500 \mathrm{mg}$ every 12 hours for sepsis.

At 78 hours AST was 1,096 U/L; ALT 2,004 U/L; LDH 1,615 U/L; PT 100.6 seconds; INR 9.87; and PLTs $7,000 / \mathrm{mm}^{3}$. Hemodialysis was performed for 4 hours, and fresh frozen plasma and platelet infusion at a dose of $1 \mathrm{U} / 10 \mathrm{~kg}$ were given. Arterial blood gas analysis showed pure respiratory alkalosis $\left(\mathrm{pH} 7.54 ; \mathrm{pCO}_{2} 23.8 \mathrm{mmHg} ; \mathrm{HCO}_{3}\right.$ $24.1 \mathrm{mmol} / \mathrm{L} ; \mathrm{BE}-1.6 \mathrm{mmol} / \mathrm{L})$.

At 84 hours the patient's serum lactate was $16.59 \mathrm{mg} / \mathrm{dL}$, ammonia $415 \mu \mathrm{g} / \mathrm{dL}$, and serum creatinine was $2.6 \mathrm{mg} / \mathrm{dL}$, so he was considered to have developed hepatorenal syndrome. His arterial blood gas values were $\mathrm{pH} 7.39 ; \mathrm{pCO}_{2} 8.4 \mathrm{mmHg}$; $\mathrm{pO}_{2} 86.8 \mathrm{mmHg} ; \mathrm{HCO}_{3} 10.4 \mathrm{mmol} / \mathrm{L}$; $\mathrm{BE}:-20.2 \mathrm{mmol} / \mathrm{L}$; and respiratory rate was 38 breaths per minute. The patient was sedated and intubated.

At 90 hours from his admission, the patient went into cardiac arrest and was revived after resuscitation. On arterial blood gas analysis; $\mathrm{pH} 7.07, \mathrm{pCO}_{2} 32.6 \mathrm{mmHg}, \mathrm{pO}_{2}$ $94.7 \mathrm{mmHg}, \mathrm{HCO}_{3} 9.9 \mathrm{mmol} / \mathrm{L}, \mathrm{BE}-18.9 \mathrm{mmol} / \mathrm{L}$ and then intravenous sodium bicarbonate, was given.

At 96 hours, the patient's AST was $329 \mathrm{U} / \mathrm{L}$;

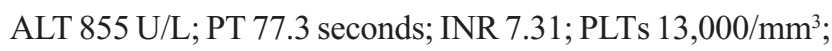
$\mathrm{Hb} 8.3 \mathrm{~g} / \mathrm{dL}$; serum creatinine $3.3 \mathrm{mg} / \mathrm{dL}$; serum lactate $112 \mathrm{mg} / \mathrm{dL} ; \mathrm{pH} 7.36 ; \mathrm{pCO}_{2} 22.3 \mathrm{mmHg} ; \mathrm{HCO}_{3} 15.3 \mathrm{mmol} / \mathrm{L}$; and $\mathrm{BE}-12 \mathrm{mmol} / \mathrm{L}$. At 98 hours after his admission, the patient went into cardiac arrest again and died.

\section{Discussion}

There are various types of wild mushrooms growing in forests and meadows which are often eaten by the local population. ${ }^{5}$

Table 3 Blood gas monitoring

\begin{tabular}{|c|c|c|c|c|c|c|c|}
\hline & $\mathrm{pH}$ & $\mathrm{pCO}_{2}(\mathrm{mmHg})$ & $\mathrm{pO}_{2}(\mathrm{mmHg})$ & $\mathrm{HCO}_{3}(\mathrm{mEq} / \mathrm{L})$ & $\mathrm{BE}(\mathrm{mmol} / \mathrm{L})$ & AG (mmol/L) & $\Delta A G(\mathrm{mmol} / \mathrm{L})$ \\
\hline On admission & 7.37 & 44 & 93 & 22 & -2.3 & 10 & \\
\hline 12 hours & 7.38 & 26.5 & 49.5 & 17.8 & -8.8 & 11.2 & \\
\hline 18 hours & 7.41 & 27.6 & 52 & 19.7 & -6.2 & 13.3 & \\
\hline 30 hours & 7.46 & 24.9 & 40 & 20.1 & -5.4 & 12.9 & \\
\hline 48 hours & 7.36 & 20.3 & 52.3 & 14.7 & -13 & 25.3 & 1.6 \\
\hline 60 hours & 7.37 & $15 . \mid$ & 64 & 12.9 & -15.8 & 31.1 & 1.9 \\
\hline 78 hours & 7.54 & 23.8 & 77 & 24.1 & -1.6 & & \\
\hline 84 hours & 7.39 & 8.4 & 86.8 & 10.4 & -20.2 & 32.6 & 1.6 \\
\hline 90 hours & 7.07 & 32.6 & 94.7 & 9.9 & -18.9 & 30.1 & $\mathrm{I} .4$ \\
\hline 96 hours & 7.36 & 22.3 & 66.7 & 15.3 & -12 & 29.7 & 2.2 \\
\hline
\end{tabular}

Abbreviations: $\triangle \mathrm{AG}$, change in anion gap; $\mathrm{AG}$, anion gap; $\mathrm{BE}$, base excess; $\mathrm{HCO}_{3}$, bicarbonate; $\mathrm{pCO}_{2}$, partial pressure of carbon dioxide; $\mathrm{pO}{ }_{2}$, partial pressure of oxygen. 
Over 5,000 species of mushrooms are presumed to be found worldwide. ${ }^{1}$ Poisonous and nonpoisonous mushrooms can be distinguished via previous experiences and observations. ${ }^{5}$ Among mushrooms, only 20\%-25\% have been named and only $3 \%$ of these are poisonous. ${ }^{1}$ Because of the relatively high number of underreported cases, the exact incidence of mushroom poisoning cannot be precisely estimated, however, amatoxin poisoning is a worldwide problem. In Western Europe, approximately 50-100 fatal cases are reported every year. ${ }^{6}$ This is less common in the United States; however, cases of amatoxin poisoning in Africa, Asia, Australia, and Central and South America have been also described. ${ }^{6}$ In Turkey, the main portion of plant toxicities comprises mushroom poisoning. The adverse effects, which range from mild gastrointestinal symptoms to major cytotoxic effects (organ failure and death), depend on the type of mushroom. It has been reported that the amatoxin-related symptoms of mushroom poisonings began at 6-24 hours after the initial ingestion, and the most common first-noticed symptoms were gastrointestinal disturbance. ${ }^{7}$

Determination of the latency period of symptoms after ingestion is very important in the treatment of mushroom poisoning because late toxicities (symptom onset more than 6 hours after ingestion) due to liver and renal failure are life-threatening and even fatal. Amatoxin poisoning must be suspected especially in patients who have jaundice after an acute gastrointestinal episode. Our patient was admitted to emergency service 36 hours after ingestion, so we observed the late toxicities. Alpha-amanitin ( $\alpha$-AMA) constitutes the main component of amatoxins, and it is presumably responsible for the toxic effect, along with beta-amanitin. ${ }^{8}$ Cooking does not destroy these amatoxins, and they can exist in the mushroom even after long periods of cold storage. ${ }^{9}$ The lethal dose may be as little as $0.1 \mathrm{mg} / \mathrm{kg}$ body weight in adults, and this amount can be adsorbed even by ingesting a single mushroom.

A considerable portion of amatoxin is taken up by hepatocytes, excreted into the bile, and reabsorbed by the enterohepatic cycle. ${ }^{10}$ The amatoxins inhibit the hepatic formation of mRNA by binding to RNA polymerase II. ${ }^{11}$ Hepatocellular uptake of $\alpha$-AMA, the major amatoxin, is followed by significant hepatocyte damage and causes acute liver failure (ALF) in Amanita phalloides intoxications. ${ }^{12}$ As a result of hepatocyte damage in the poisonings with Amanita species, AST and ALT levels increase in the serum. ${ }^{13}$ Eren et $\mathrm{al}^{14}$ showed that the patients who died had very high AST (2,075-3,464 U/L ) and ALT (2,345-4,048 U/L) levels. It was reported that patients developed hepatic coma after AST and ALT values rose, demonstrating a significant relationship between mortality and AST and ALT levels. As a result of this, AST and ALT levels can be used as a prognostic marker of mushroom poisoning or an indication for liver transplantation. ${ }^{14}$ Increases in LDH levels, as a result of leakage, can be used as a good marker of cell damage because it is located almost entirely in the cytoplasm. ${ }^{15}$ Thus, it can be concluded that decreased viability of hepatocytes treated with $\alpha$-AMA was related to significant morphological derangements (disruption of cell membrane). In our case, AST, ALT, and LDH always remained high. After receiving hemodialysis and fresh frozen plasma replacement on the twelfth hour these values showed a slight decrease, and then increased again. The clinical picture of Amanita phalloides poisoning can range from a mild subclinical presentation to a lethal fulminant course. As a result, not all patients with Amanita phalloides poisoning develop ALF and have a fatal outcome. Amanita phalloides intoxication has four consecutive phases in the classical course: lag phase, gastrointestinal phase, apparent convalescence, and ALF. ALF is the last phase in which the transaminases rise dramatically and liver and renal function deteriorate. This process results in hyperbilirubinemia, coagulopathy, hypoglycemia, acidosis, hepatic encephalopathy, and hepatorenal syndrome. ${ }^{16}$ Multiorgan failure, disseminated intravascular coagulation, mesenteric thrombosis, convulsions, and death may result within 1-3 weeks after ingestion. ${ }^{17}$ Our patient was diagnosed with ALF because of high ammonia levels, flapping tremor, and hepatorenal syndrome. Despite our quick contact with the liver transplantation center, the patient was refused because of the colon carcinoma. ${ }^{18}$ The contraindications of liver transplantation in acute liver failure is mentioned in Table 4.

Metabolic acidosis is associated with substantial morbidity and mortality, and it is a frequent acid-base disturbance

Table 4 Contraindications for liver transplant in acute liver failure Cardiopulmonary disease that cannot be corrected and is a prohibitive risk for surgery.

Malignancy outside of the liver within 5 years of evaluation (not including superficial skin cancers) or not meeting oncologic criteria for cure.

Active alcohol and drug use. Most programs require a minimum period of abstinence of at least 6 months with participation in a structured rehabilitation and abstinence program and adequate social support to help maintain sobriety.

Advanced age and AIDS are examples of relative contraindications that are site-specific and are often decided on a case-by-case basis. Liver transplantation can be performed in those older than 65 provided that there has been a comprehensive search made for comorbidities.

Abbreviation: AIDS, acquired immunodeficiency syndrome. 
seen in hospitalized patients. ${ }^{19}$ Lactic acidosis is the most frequent cause of metabolic acidosis in hospitalized patients. It is characterized by a high AG metabolic acidosis (AG $>12 \mathrm{mmol} / \mathrm{L}$ ) with increased serum lactate concentrations $(>5 \mathrm{mEq} / \mathrm{L})$ and carries a significant risk for mortality. Tissue hypoperfusion and hypoxia encountered in metabolic acidosis commonly result in clinical situations such as shock and sepsis. ${ }^{19}$ However, the present patient developed this acid-base abnormality in the presence of normal tissue perfusion and oxygenation. Many drugs have been implicated in the pathogenesis of lactic acidosis. ${ }^{20}$ Moreover, toxicity of amatoxin (the toxin isolated from Amanita phalloides) is commonly characterized by severe normal AG metabolic acidosis, which has been attributed to fulminant hepatic failure and tubular necrosis. ${ }^{21}$ Although amatoxin is rapidly cleared by the kidneys, its direct nephrotoxicity to the proximal and distal convoluted tubules may lead to acute tubular necrosis. ${ }^{21}$ Lactic acidosis progresses despite hemodialysis when blood lactate is produced faster than it can be cleared. As shown in a previous case report, if the clinical and biochemical evaluation of the patient shows signs of acidosis, hemodialysis must be performed quickly and for a prolonged period of time. ${ }^{22}$ The rising lactate level and high AG metabolic acidosis in our patient were attributed to lactic acidosis and so hemodialysis was performed. Because of lactic acidosis, we extended the duration of hemodialysis. The presence of lactic acidosis and hepatorenal syndrome was directly related with the mortality of the patient.

Severe mushroom intoxication caused by amanitin remains an unresolved problem in clinical toxicology because no specific and fully efficient antidote is readily available. Several substances (steroids, cimetidine, thioctic acid, etc) which were widely used in the past have been documented to be completely ineffective in the treatment of mushroom poisoning. Moreover, a retrospective analysis revealed that the current, most commonly used antidote, benzylpenicillin, shows poor clinical efficacy. ${ }^{23}$ Overall results of a meta-analysis indicate that silibinin or acetylcysteine are found to be more effective in mushroom poisoning therapy in humans. ${ }^{24}$ However, acetylcysteine, silibinin, and benzylpenicillin were found to be ineffective in limiting hepatic injury after $\alpha$-AMA poisoning in a murine model. ${ }^{25}$ Our patient did not respond to the combination therapy of acetylcysteine, silibinin, benzylpenicillin, steroids, thioctic acid, and multivitamins.

The major parameter in the treatment of mushroom poisoning is the time of admission to hospital after ingestion. The accidental consumption of poisonous mushrooms picked from their natural source presents a significant health problem, and clinicians should attempt to raise public awareness.

\section{Disclosure}

The authors report no conflicts of interest in this work.

\section{References}

1. Gonmori K, Yoshioka N. The examination of mushroom poisonings at Akita University. Leg Med (Tokyo). 2003;5 Suppl 1:S83-S86.

2. Lin YM, Wang TL. Mushroom poisoning. Ann Disaster Med. 2004;3: $8-11$.

3. Trestrail JH. Mushroom poisoning in the United States - an analysis of 1989 United States Poison Center data. J Toxicol Clin Toxicol. 1991;29(4):459-465.

4. Barbato MP. Poisoning from accidental ingestion of mushrooms. Med J Aust. 1993;158(12):842-847.

5. No authors listed. Mushroom poisoning. Lancet. 1980;2(8190):351-352.

6. Karlson-Stiber C, Persson H. Cytotoxic fungi - an overview. Toxicon. 2003;42(4):339-349.

7. Kaufmann P. [Mushroom poisonings: syndromic diagnosis and treatment]. Wien Med Wochenschr. 2007;157(19-20):493-502. German.

8. Dart RC, editor. Mushrooms. In: Medical Toxicology. 3rd ed. Philadelphia, PA: Lippincott Williams \& Wilkins; 2004:1719-1735.

9. Himmelmann A, Mang G, Schnorf-Huber S. Lethal ingestion of stored Amanita phalloides mushrooms. Swiss Med Wkly. 2001;131(41-42): 616-617.

10. Cole FM. A puppy death and Amanita phalloides. Aust Vet J. 1993; 70(7):271-272.

11. Kröncke KD, Fricker G, Meier PJ, Gerok W, Wieland T, Kurz G. Alpha-Amanitin uptake into hepatocytes. Identification of hepatic membrane transport systems used by amatoxins. J Biol Chem. 1986;261(27):12562-12567.

12. Schneider SM. Mushrooms. In: Ford MD, Delaney KA, Ling LJ, Erickson T, editors. Clinical Toxicology. Philadelphia, PA: Saunders Company; 2001:899-909.

13. Kendrick B. Mushroom poisoning - analysis of two cases, and a possible new treatment, plasmapheresis. Mycologia. 1984;76(3):448-453.

14. Eren SH, Demirel Y, Ugurlu S, Korkmaz I, Aktas C, Güven FM. Mushroom poisoning: retrospective analysis of 294 cases. Clinics (Sao Paulo). 2010;65(5):491-496.

15. Legrand C, Bour JM, Jacob C, et al. Lactate dehydrogenase (LDH) activity of the cultured eukaryotic cells as marker of the number of dead cells in the medium [corrected]. J Biotechnol. 1992;25(3): 231-243.

16. Paaso B, Harrison DC. A new look at an old problem: mushroom poisoning. Clinical presentations and new therapeutic approaches. $\mathrm{Am}$ J Med. 1975;58(4):505-509.

17. Sanz P, Reig R, Borrás L, Martinez J, Máñez R, Corbella J. Disseminated intravascular coagulation and mesenteric venous thrombosis in fatal Amanita poisoning. Human Toxicol. 1988;7(2):199-201.

18. Cross TJ, Antoniades CG, Muiesan P, et al. Liver transplantation in patients over 60 and 65 years: an evaluation of long-term outcomes and survival. Liver Transpl. 2007;13(10):1382-1388.

19. Adrogué HJ. Metabolic acidosis: pathophysiology, diagnosis and management. J Nephrol. 2006;19(Suppl 9):S62-S69.

20. Liamis G, Milionis HJ, Elisaf M. Pharmacologically-induced metabolic acidosis: a review. Drug Saf. 2010;33(5):371-391.

21. Broussard CN, Aggarwal A, Lacey SR, et al. Mushroom poisoning from diarrhea to liver transplantation. Am J Gastroenterol. 2001;96(11): 3195-3198.

22. Avcı D, Çetinkaya A, Karahan S, et al. Suicide commitment with metformin: our experience with five cases. Ren Fail. 2013;35(6): 863-865. 
23. Enjalbert F, Rapior S, Nouguier-Soulé J, Guillon S, Amouroux N, Cabot C. Treatment of amatoxin poisoning: 20-year retrospective analysis. J Toxicol Clin Toxicol. 2002;40(6):715-757.

24. Magdalan J, Ostrowska A, Piotrowska A, et al. Failure of benzylpenicillin, $\mathrm{N}$-acetylcysteine and silibinin to reduce alphaamanitin hepatotoxicity. In Vivo. 2009;23(3):393-399.
25. Tong TC, Hernandez M, Richardson WH, et al. Comparative treatment of alpha-amanitin poisoning with $\mathrm{N}$-acetylcysteine, benzylpenicillin, cimetidine, thioctic acid, and silybin in a murine model. Ann Emerg Med. 2007;50(3):282-288.

\section{Publish your work in this journal}

The International Medical Case Reports Journal is an international, peer-reviewed open-access journal publishing original case reports from all medical specialties. Previously unpublished medical posters are also accepted relating to any area of clinical or preclinical science. Submissions should not normally exceed 2,000 words or
4 published pages including figures, diagrams and references. The manuscript management system is completely online and includes a very quick and fair peer-review system, which is all easy to use. Visit $\mathrm{http}: / / \mathrm{www}$.dovepress.com/testimonials.php to read real quotes from published authors.

Submit your manuscript here: http://www.dovepress.com/international-medical-case-reports-journal-journal 